\title{
Immersion vaccination for control of fish furunculosis
}

\author{
C. J. Rodgers \\ Ministry of Agriculture, Fisheries and Food, Directorate of Fisheries Research, Fish Diseases Laboratory, Weymouth, Dorset DT4 8UB, \\ United Kingdom
}

\begin{abstract}
This immersion vaccination study used rainbow trout Salmo gairdneri and compared the efficacy of a vaccine alone with one containing liposome particles against a natural challenge of fish furunculosis. Results indicated that fry could be protected with a 3-component vaccine consisting of whole cells, 'toxoided' extracellular products, and lipopolysaccharide and that the protection level was significantly enhanced when the vaccine also contained liposomes. In addition, vaccinated fish appeared to be significantly larger than control fish.
\end{abstract}

Furunculosis, caused by Aeromonas salmonicida, is one of the most economically important diseases of farmed fish and it is only very recently that a commercially available vaccine for mass immunization of fry has been licenced for use in the UK. The search for a successful vaccine has had a long and chequered history, with laboratory work proving that it is possible to protect fish with orally administered (Duff 1942, Klontz 1967 ) or injected preparations (Krantz et al. 1964, Paterson \& Fryer 1974, Cipriano 1982). However, field trials have so far been inconclusive with some workers achieving no apparent protection (Klontz 1969, Udey \& Fryer 1978), while others have reported slight (Hara et al. 1976) or good protection (Palmer \& Smith 1980, Smith et al. 1980, Austin \& Rodgers 1981).

The composition of potential vaccines has been centred around the use of formalised whole cells of Aeromonas salmonicida. There has been growing evidence, however, that extra-cellular toxins (ECP) not only play an important role in the pathogenicity of $A$. salmonicida (Fuller et al. 1977, Ellis et al. 1981), but are immunogenic and also remain toxic after inactivation of the bacterial cells with formalin (Austin \& Rodgers 1981). The endotoxin (LPS) component, present in strains of A. salmonicida (Aoki \& Trust 1984), has also been associated with protection (Munn et al. 1982, McCarthy et al. 1983) and is deemed to be antigenic (Cipriano \& Pyle 1985).
The potential of combining all 3 bacterial components into a vaccine for immunizing rainbow trout fry has already been reported (Rodgers \& Austin 1985). The study outlined here further develops this approach and compares the effectiveness of 2 delivery methods immersion in a vaccine bath with and without liposome particles - for administration of the bacterin to fry.

Liposomes are vesicles of phospholipid which spontaneously form into concentric bi-layers when they come into contact with aqueous solutions. Particles contained in solution become trapped between the bilayers which, being biodegradable, slowly release their contents as they are broken down within biological systems. Therefore, liposomes may act as vaccineadjuvants because of the slow release of antigen. The liposomes employed were composed of naturally occurring phosphatidylcholine; this substance is itself a poor antigen (Alving 1977), but it has been used successfully as an immuno-adjuvant (van Rooijen \& van Nieuwmegan 1980).

Materials and methods. The components of each vaccine were prepared from a virulent strain of Aeromonas salmonicida (designated 3SA) isolated from rainbow trout Salmo gairdneri and maintained on Brain Heart Infusion agar (BHI; Oxoid). Bacteria were grown on BHI in large, square bioassay plates (Nunc; Gibco) overlayered with unplasticised cellulose film and harvested using the method of Austin \& Rodgers (1981).

Toxoid was prepared from harvested cells using an inactivation process involving 3 sequential treatments with: $5 \%(\mathrm{v} / \mathrm{v})$ formalin for $14 \mathrm{~d}$ at $37^{\circ} \mathrm{C} ; 10 \%(\mathrm{v} / \mathrm{v})$ chloroform for $14 \mathrm{~d}$ at room temperature; and $0.1 \mathrm{M}$ lysine hydrochloride for $14 \mathrm{~d}$ at $22^{\circ} \mathrm{C}$. The lipopolysaccharide (LPS) component was extracted using the hot phenol method of Sutherland \& Wilkinson (1971). This technique produces LPS free of protein and loosely bound phospholipid (McCartney \& Wardlaw 1985). 
Liposomes were prepared by dissolving $600 \mathrm{mg}$ of phosphatidylcholine in $25 \mathrm{ml}$ chloroform. The chloroform was then removed by rotary evaporation at $37^{\circ} \mathrm{C}$ and $20 \mathrm{ml}$ of the vaccine components mixture, suspended in phosphate-buffered saline, was added. The vaccine components mixture contained formalin-inactivated whole cells of Aeromonas salmonicida at a concentration of $2.65 \times 10^{9}$ cells $\mathrm{ml}^{-1}$, inactivated toxin

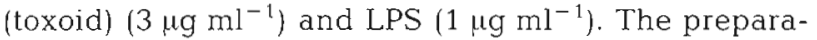
tion was gently mixed by shaking with a few small, sterile glass beads until homogeneous

Host efficacy testing of the vaccine preparations used 3 identical groups of 1300 all-female rainbow trout fry at a field site with an annual history of furunculosis. The trial began in May 1983 when the first group of fish was immersed for 2 min in 21 of the vaccine. The second group of fry was also vaccinated by immersion for $2 \mathrm{~min}$ in $2 \mathrm{l}$ of the vaccine. Although the second vaccine contained an identical final concentration of the $3 \mathrm{vac}-$ cine components, ca $30 \%$ of the components were contained within liposomal vesicles. The proportion of vaccine mixture encapsulated in liposomes was determined by measuring the free protein (Read \& Northcote 1981) before and after incapsulation by the liposomes. After a 2 min contact period each group of fish was transferred to separate $200 \mathrm{l}$ polypropylene tanks with each being independently supplied with constant running fresh water from a public reservoir at an initial temperature of $11.5^{\circ} \mathrm{C}$. The third group served as unvaccinated controls. All groups were fed normally up to 6 times a day for the duration of the trial. Any moribund or dead fish were examined for Aeromonas salmonicida by plating kidney material onto tryptone soya agar (TSA; Oxoid). The plates were incubated at $22^{\circ} \mathrm{C}$ for $5 \mathrm{~d}$. Aeromonas salmonicida was confirmed by the latex agglutination test (McCarthy 1975).
Table 1 Salmo gairdneri. Mortality $(\%)$ of vaccinated and control fish during natural furunculosis challenge

\begin{tabular}{|c|c|c|c|}
\hline \multirow[t]{2}{*}{ Week } & \multicolumn{3}{|c|}{ Mortality $(\%)$} \\
\hline & $\begin{array}{l}\text { Vaccine } \\
\text { without } \\
\text { liposomes }\end{array}$ & $\begin{array}{c}\text { Vaccine } \\
\text { with } \\
\text { liposomes }\end{array}$ & Control \\
\hline 10 & 1.0 & 1.0 & 0.2 \\
\hline 11 & 0.2 & 0.6 & 13.2 \\
\hline 12 & 2.4 & 2.4 & 20.5 \\
\hline 13 & 2.7 & 0.9 & 1.6 \\
\hline 14 & 3.9 & 0.8 & 0.5 \\
\hline 15 & 0.4 & 0.5 & 0.4 \\
\hline
\end{tabular}

Results and discussion. The first signs of furunculosis appeared in unrelated stocks of rainbow trout also held at the experimental site. The disease occurred during June as the water temperature reached $16^{\circ} \mathrm{C}, 5 \mathrm{wk}$ after vaccination. Aeromonas salmonicida was isolated from kidney material taken from these fish. Furunculosis was not confirmed bacteriologically in immunized fish until $11 \mathrm{wk}$ post-vaccination, during August, after the water temperature had reached 18 to $19^{\circ} \mathrm{C}$. At this point, control fish had a weekly mortality rate of about $13 \%$; by Week 12 this had risen to ca $20 \%$ following which the mortalities declined to $1.6 \%$ in Week 13 and to $0.5 \%$ in Week 14. Losses due to furunculosis in the 2 vaccinated groups during this period were much lower, with the non-liposome vaccine group having weekly mortalities of $0.2,3,3.4$, and $5 \%$ before declining to $0.4 \%$ in Week 15 , and the liposome vaccine group sustaining corresponding losses of $0.7,3,1,1$, and $1 \%$ (Table 1 ). Cumulative mortalities due to furunculosis from the start of the experiment to its termination at Week 18 show the losses to

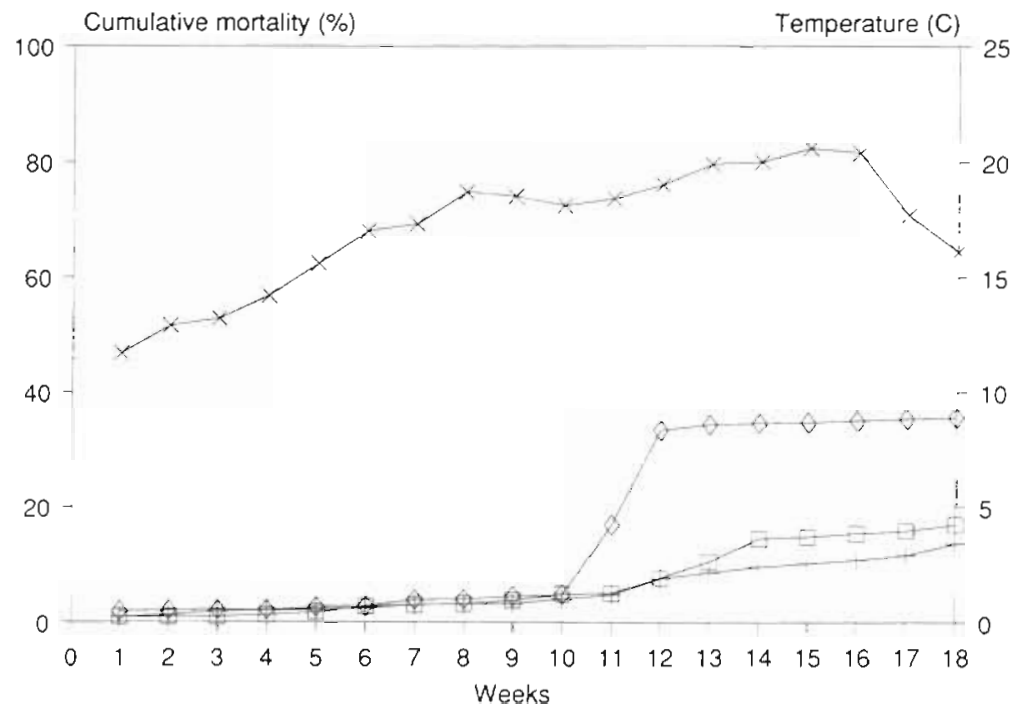

Fig. 1 Salmo gairdneri. Cumulative mortality in vaccinated and control fish. (口) Vaccine without liposomes; (+) vaccine with liposomes; $(\diamond)$ control: $(x)$ water temperature 
be $15.1 \%$ (196 fish) for the non-liposome vaccine group, $11.4 \%$ (148 fish) for the liposome vaccine group, and $37.3 \%$ (485 fish) for the control group. By Chisquare analysis, survival in the treated groups was significantly better $(p<0.001)$ than that of the control group. Interestingly also, survival in the liposome vaccine group was significantly better than that of the nonliposome vaccine group (Chi-square, $p<0.01$ ).

At the end of the trial all the fish from each group were weighed to determine whether or not their overall growth rate had been affected. The control group had 181 fish $\mathrm{kg}^{-1}$ compared with 148 fish $\mathrm{kg}^{-1}$ for the nonliposome vaccine group and 134 fish $\mathrm{kg}^{-1}$ for the liposome vaccine group. By Student's t-test analysis, fish in the vaccinated groups were significantly larger than those of the control group $(p<0.001)$ and it was also observed that they appeared to have less fin-rot than control fish. In addition, fish in the liposome treated group were larger than those in the non-liposome treated group (t-test, $\mathrm{p}<0.001$ ). Vaccination was the main variable accounting for this effect. Other factors such as husbandry, handling, and non-specific stress were the same for each group throughout the trial. The density of fish in the vaccinated groups became greater than that in the control group as the furunculosis outbreak progressed. However, the density increase did not appear to be stressful and the feeding rate was adjusted appropriately as the trial progressed.

The use of liposomes in fish vaccines has not previously been reported. However, the slow release of antigen by the biodegradable liposome reported to occur in mammalian studies (Fendler 1980, Gregoriadis 1980 ) indicated that liposomes could prove useful for fish vaccination. Johnson \& Amend (1984) suggested that booster vaccination enhances protective immunity against furunculosis. However, with the use of liposomes repeated vaccination may prove to be unnecessary.

Recent work has indicated that uptake of Aeromonas salmonicida cells can be enhanced by the addition of $0.81 \mu \mathrm{m}$ latex particles to the cell suspension in which the fish are to be immersed (Hodgkinson et al. 1987). The superior protection observed with the liposome vaccine may, therefore, be due in part to enhanced uptake of protective antigen mediated by the liposome particles, some of which are comparable in size to latex particles (Papahadjopoulos \& Miller 1967).

Despite considerable study (Sakai 1985, Fyfe et al. 1986), the identity of the immunogens produced by Aeromonas salmonicida is still uncertain. Consequently, it is not known whether the vaccines used in the present study could be simplified by omitting any of their components. Unpurified ECP has been shown to be protective when 'toxoided' by formalin and chloroform and then stablished with lysine (Rodgers \&
Austin 1985). However, whether proteases (Shieh 1984, Sakai 1985) or haemolysins present in the ECP were responsible for the immunogenicity is doubtful, as these factors are poorly antigenic in rainbow trout (Ellis et al. 1988). Also, the role of endotoxin (LPS) in the vaccine is not clear. LPS has been reported to be protective against furunculosis when administered with adjuvant (Cipriano \& Pyle 1985), but whether it functioned as an antigen or by virtue of its ability to stimulate phagocytic activity (MacArthur \& Fletcher 1985) and therefore non-specific immunity (Ellis 1988) is unknown. Clearly, further work is needed to clear up the foregoing questions and to study the usefulness of liposomes in fish vaccines. It is hoped that the promising findings reported here will stimulate the needed studies.

\section{LITERATURE CITED}

Alvin, C. R. (1977). Immune reactions of lipids and lipid model membranes. In: Sela, M. (ed.) The antigens, Vol. 4 Academic Press, New York, p. 1-15

Aoki, T., Trust, T J. (1984). Electrophoretic analysis of the lipopolysaccharide from Aeromonas salmonicida strains isolated in Japan. Bull. Jap. Soc. scient. Fish. 50: 1789

Austin, B., Rodgers, C. J. (1981). Evaluation of Aeromona.s salmonicida vaccines. Develop. Biol. Standard. 49: $387-393$

Cipriano, R. C. (1982). Immunogenic potential of growth products extracted from cultures of Aeromonas salmonicida for brook trout (Salvelinus fontinalis). Can. J. Fish. Aquat. Sci. 39: 1512-1518

Cipriano, R. C., Pyle, S. W (1985). Adjuvant-dependent immunity and the agglutinin response of fishes against Aeromonas salmonicida, cause of furunculosis. Can. J. Fish. Aquat. Sci. 42: 1290-1295

Duff, D. C. B. (1942). The oral immunisation of trout against Bacterium salmonicida. J. Immunol. 44: 81-94

Ellis, A. E., Hastings, T. S., Munro, A. L. S. (1981). The role of Aeromonas salmonicida extracellular products in the pathology of furunculosis. J. Fish Dis. 4: 41-51

Ellis, A. E. (1988). Current aspects of fish vaccination. Dis. aquat. Org. 4: 159-164

Ellis, A. E., Burrows, A. S., Stapleton, K. J. (1988) Lack of relationship between virulence of Aeromonas salmonicida and the putative virulence factors: A-layer extracellular proteases and extracellular haemolysins. J. Fish Dis. 11: 309-323

Fendler, J H. (1980). Optimising drug entrapment in liposomes. Chemical and biophysical considerations. In: Gregoriadis, G., Allison, A. C. (ed.) Liposomes in biological systems, Chap. 3. J. Wiley and Sons Ltd, Chichester, p. $87-100$

Fuller, D. W., Pilcher, K. S., Fryer, J. L. (1977). A leucocytolytic factor isolated from cultures of Aeromonas salmonicida. J. Fish. Res. Bd Can. 34: 1118-1125

Fyfe, L., Finley, A., Coleman, G., Munro, A. L. S. (1986). A study of the pathological effect of isolated Aeromonas salmonicida extracellular protease on Atlantic salmon, Salmo salar. J. Fish Dis. 9: 403-409

Gregoriadis, G. (1980). The liposome drug-carrier concept: its development and future. In: Gregoriadis, G., Allison, A. C. 
(ed.) Liposomes in biological systems. Chap. 2. J. Wiley and Sons Ltd, Chichester, p. 25-86

Hara, T., Inoue, K., Morikawa, S., Tashiro, F. (1976). Vaccination trials for control of furunculosis in salmonids in Japan. Fish Pathol. 10 (2): 227-235

Hodgkinson, J. L., Bucke, D., Austin, B. (1987) Uptake of the fish pathogen, Aeromonas salmonicida, by rainbow trout (Salmo gairdneri). Microbıos Lett. 40: 207-210

Johnson, K. A., Amend, D. F. (1984). Potential for immersion vaccination against Aeromonas salmonicida. J. Fish Dis. 7: $101-105$

Klontz, G. W. (1967). Immunopathology. In: Progress in sport fishery research 1966. U.S. Bureau of Sport Fishery and Wildlife Resources Publ. No. 39: 81-82

Klontz, G. W. (1969). Immunopathology. In: Progress in sport fishery research 1968. U.S. Bureau of Sport Fishery and Wildlife Resources Publ. No. 77: 8-12

Krantz, G. E., Redecliff, J. M., Heist, C. E. (1964). Immune response of trout to Aeromonas salmonicida. Part 1. Development of agglutinating antibodies and protective immunity. Progve Fish Cult. 26: 3-10

MacArthur, J. I., Fletcher, T. C. (1985). Phagocytosis in fish. In: Manning, M. J., Tatner, M. F. (ed.) Fish immunology. Academic Press, London, p. 29-46

McCarthy, D. H. (1975). Detection of Aeromonas salmonicida antigen in diseased fish tissue. J. gen. Microbiol. 88: 384-386

McCarthy, D. H., Amend, D. F., Johnson, K. A., Bloom, J. V. (1983) Aeromonas salmonicida: determination of an antigen associated with protective immunity and evaluation of an experimental bacterin. J. Fish Dis. 6: 155-174

McCartney, A. C., Wardlaw, A. C. (1985). Endotoxic activities of lipopolysaccharides. In: Stewart-Tull, D. E. S., Davies, M. (eds.) Immunology of the bacterial cell envelope, Chap. 8. J. Wiley and Sons Ltd, Chichester, p. 203-238

Munn, C. B., Ishiguro, E. E., Way, W W., Trust, T J. (1982). Role of surface components in serum resistance of virulent Aeromonas salmonicida. Infection Immunity 36 (3): 1069-1075

Palmer, R., Smith, P. R. (1980). Studies on vaccination of

Responsible Subject Editor: Dr T. Evelyn, Nanaimo, B.C., Canada
Atlantic salmon against furunculosis. In: Ahne, W. (ed.) Fish diseases. Third COPRAQ-session. Springer-Verlag, Berlin, p. 107-112

Papahadjopoulos, D., Miller, N. G. A. (1967). Phospholipid model membranes. I. Structural characteristics of hydrated liquid crystals. Biochim. Biophys. Acta 135: 624-638

Paterson, W. D., Fryer, J. L. (1974). Immune response of juvenile coho salmon (Oncorhynchus kisutch) to Aeromonas salmonicida cells administered intraperitoneally in Freund's complete adjuvant. J. Fish. Res. Bd Can. 31: $1751-1755$

Read, S. M., Northcote, D. H. (1981). Minimization in the response to different proteins of the Coomassie Blue $G$ dye binding assay for protein. Analyt. Biochem. 116: 53-64

Rodgers, C. J., Austin, B. (1985). Oral immunisation against furunculosis: an evaluation of two field trials. In: Manning, M. J., Tatner, M. F. (eds.) Fish immunology. Academic Press, London, p. 185-194

van Rooijen, N., van Nieuwmegan, R. (1980). Endotoxin enhanced adjuvant effect of liposomes, particularly when antigen and endotoxin are incorporated within the same liposome. Immunol. Commun. 9: 747-757

Sakai, D. K. (1985). Efficacy of specific antibody against agglutinating Aeromonas salmonicida strains on infectivity and vaccination with inactivated protease. J. Fish Dis. 8: $397-405$

Shieh, H. S. (1984). Vaccination of Atlantic salmon against furunculosis with protease of a virulent strain of Aeromonas salmonicida. Microbios Lett. 25: 131-134

Smith, P. D., McCarthy, D. H., Paterson, W. D. (1980). Further studies on furunculosis vaccination. In: Ahne, W. (ed.) Fish diseases, Third COPRAQ-session. Springer-Verlag, Berlin, p. $113-119$

Sutherland, I. W., Wilkinson, J. F. (1971). Chemical extraction methods of microbial cells. In: Norris, J. R., Ribbons, D. W (eds.) Methods in microbiology 5b. Academic Press, London, p. 345-383

Udey, L. R., Fryer, J. L. (1978). Immunization of fish with bacterins of Aeromonas salmonicida. Mar. Fish. Rev. 40: $12-17$

Manuscript first received: August 15, 1988

Revised version accepted: November 29, 1989 